\title{
De la estetica generalizada a la estetica difusa
}

\author{
ROMÁN DE LA CALLE \\ Universidad de Valencia
}

LA NOCIÓN DE ESTETICIDAD DIFUSA se ha convertido en un eficaz concepto explicativo, al operar de lleno en el presente contexto cultural, quizás como uno de sus rasgos más destacados, consagrándose en su uso, comúnmente junto a otras expresiones no menos cargadas también de relativa actualidad, tales -por ejemplo- como pensamiento débil o proyecto dulce, por hacer escueta referencia a determinados planteamientos colaterales, quizás no menos conocidos y, además, ya ampliamente barajados en los múltiples debates de la tardomodernidad que, sin duda, ha definido, de manera resuelta, nuestro reciente pulso histórico.

Precisamente para mejor respaldar, desde un principio, esta aproximación al concepto de esteticidad difusa es posible que, al menos metodológicamente, nos convenga correlacionarlo, por oposición, con aquella otra noción histórica de estética generalizada, la cual-como es bien sabido-subyace extensivamente a los proyectos renovadores de la modernidad y, en concreto, se explicita a través de las plurales actividades a que dan lugar determinadas poéticas de la vanguardia histórica, en su compartida y tenaz aproximación entre arte y vida.

Entre la estética generalizada y la estética difusa ha mediado nada menos que todo un siglo. De hecho, entre las décadas iniciales del XX y los inicios del XXI la historia ha pasado múltiples y variadas páginas, con una aceleración y una intensidad realmente novedosas.

Desde esta óptica comparativa, a menudo se han esquematizado globalmente, aunque de manera algo simplista, tales relaciones conceptuales a través de la socorrida fórmula: «estética difusa versus estética generalizada». Sin embargo, asumir estrictamente tal dualidad -así formulada-implicaría, ante todo, el establecimiento, a ultranza, de una radicalizada oposición entre ambas nociones, al igual que se ha venido haciendo -mutatis mutandis-entre los versátiles y socorridos ámbitos de la modernidad y la posmodernidad. 
Sin duda alguna, es fácil descubrir, en el binomio estética difusa / estética generalizada elementos de franca oposición, pero no por ello conviene ciertamente minimizar las posibles pautas de continuidad y paulatina transformación presentes asimismo en la fluyente dualidad de planteamientos que -en el devenir de nuestra tradición de cultura- han supuesto tanto la adscripción histórica de las vanguardias a una estética generalizada como el desarrollo posterior del contexto propio de la actual esteticidad difusa.

Quizás, más bien, descriptivamente podrían entenderse ambas nociones como los límites extremos que enmarcan la consumación histórica de un complejo continuum. De este modo, consideradas como potenciales situaciones «extremas», cabría, sin duda, la directa apelación a la partícula versus, en la estructuración sistemática de sus drásticas contraposiciones conceptuales. Pero por otra parte, si queremos tener en cuenta, ante todo, la realidad fluyente y transitoria del entero continuum que diacrónicamente las enlaza, habría que acentuar más bien, en su adecuada medida, los plurales meandros históricos y las paulatinas transformaciones que, de hecho, han conducido de la una a la otra.

Dicho de otra manera, ¿hasta qué extremo es justo afirmar que ya en los postulados mismos de la estética generalizada, es decir en el seno de aquel intenso y obsesivo afán vanguardista por acercar programáticamente el arte a la vida, laten ya sin duda -aunque sea sólo in nuce-ciertas condiciones de posibilidad y determinadas líneas de fuerza, que, a la larga, irán luego dando paso (al enfrentarse a otros contextos existenciales, con el afianzamiento de nuevos medios tecnológicos y, sobre todo, al socaire de otros objetivos instrumentales) a las efectivas transformaciones que comporta el despliegue de la vigente esteticidad difusa?

En realidad, tanto tras la concepción de la estética generalizada -que históricamente se hace fuerte al hilo de las utopías antropológicas de la modernidad-como tras el vigente contexto de la esteticidad difusa, conviene recordar -una vez más- la compleja interrelación existente entre lo que ha sido denominado, en general, la dimensión estética humana (con su carácter universal, que tiende a fijar condensadamente y a transmitir, haciéndolas perdurables, las experiencias estéticas, como representaciones simbólicas) y la dimensión artística, comúnmente considerada como la esfera privilegiada -dotada de relativa autonomía institucional, en el marco de nuestra tradición de cultura- de las propias experiencias estéticas.

De hecho los posibles tránsitos e intercambios entre la dimensión artística y la dimensión estética se configuran siempre, específica e históricamente, en cada contexto cultural. Y en ambas dimensiones, así como en sus mutuas conexiones y refuerzos, el papel de la educación ha sido y es fundamental y definitivo.

En la modernidad, la dimensión artística se toma abiertamente como modelo de la dimensión estética. Justamente de ahí nacen los presupuestos de la 
estética generalizada, promoviendo, en intensidad, la proyección sobre la vida de los parámetros y comportamientos específicamente artísticos, dando lugar, de este modo, a las correspondientes utopías antropológicas de liberación y emancipación -tanto del sujeto, como de la sociedad- a través del arte, que resuenan con fuerza en las vanguardias y el movimiento moderno, como vehículos privilegiados de una singular paideia, donde tanto los postulados de la autonomía como los de la funcionalidad del arte no han dejado polémicamente de entrecruzarse.

No en vano, por ejemplo, las funciones de emancipación y enriquecimiento del plano sensible (educación de los sentidos) desempeñadas por la dimensión artística, se han alineado estrechamente con la función social de transmisión simbólica de valores que el arte -soporte y vehículo- ejercita, bien sea como vitalidad renovada de lo existente o como anticipación crítica y proyecto de nuevos valores emergentes.

Es así como la dimensión artística -en cuanto esfera privilegiada y fundamental de institucionalización de la experiencia estética-, uniendo lo sensible con lo axiológico, se abre funcionalmente a la constitución (producción y transmisión), de nuevas esferas de sentido en la formación humana.

Desde esta óptica, la propuesta de la educación a través del arte se perfila con todo su alcance. Del arte -de la dimensión artística asumida como paradigma- se pasa llanamente a la dimensión estética, y ésta queda catapultada ya como estética generalizada, es decir abrazada directamente a la vida, en su globalidad, pero quizás también -recordémoslo- con el riesgo de diluirse en ella, aunque pretendiendo paradójicamente, a la vez, mantener así en el plano mismo de la cotidianidad, los rasgos, la incidencia y los objetivos creativos y emancipatorios propios del arte. La vida -transformada y redimida- como obra de arte total.

En realidad la estética generalizada se traduce, de hecho, en una especie de revulsiva ideología estética, que postula radicalmente, de este modo, la armónica integración del individuo y el ambiente social, la educación del «hombre entero», que, con ejemplar intensidad, soñaba ya el viejo F. Schiller desde sus célebres e inolvidables Cartas para la educación estética.

Ahora bien, históricamente esta concreta perspectiva estética, que recorre los caminos de la modernidad, cohabita además necesariamente con otras perspectivas no menos determinantes, tales como la perspectiva tecnológica y la perspectiva política. Y con ellas, en cuanto estética generalizada, tuvo que medir asimismo sus fuerzas, pretendiendo presentarse -con su carácter de utopía antropológica- bien sea como su recurso alternativo o bien como opción integradora, siempre en complejo diálogo con estas otras citadas perspectivas.

Reiteradamente se ha venido hablando, a lo largo de nuestra posmodernidad-al reconsiderar los matices que ha presentado esta estética generalizada-, 
de proyectos inconclusos, de sorprendentes descréditos o de preanunciados agotamientos. Pero, de hecho, podríamos reflexionar, también, acerca de si históricamente la postulación misma de la estética generalizada como alternativa emancipadora frente a la perspectiva política y/o la perspectiva técnico-científica podía realmente zafarse de su propio impasse como contrastada utopía. ¿Tenía realmente posibilidades tal oposición? ¿Puede resistir la perspectiva estética sistemáticamente distanciada de la perspectiva tecnológica y/o enfrentada a la perspectiva política?

Por otro lado, cabría asimismo reconsiderar desapasionadamente y con la debida distancia la historia de los numerosos y efervescentes proyectos, puestos en marcha por las propias vanguardias, en vistas a correlacionar e integrar la perspectiva estética, por ejemplo, tanto con la perspectiva política como con la perspectiva tecnológica, en sus plurales estrategias y distintos afanes emancipatorios.

¿Hasta qué extremo tal auspiciada integración -desde la estética generalizada- no preanunciaba ya de algún modo (junto a la proyección radical del arte en la vida, con la propuesta de construcción de otra realidad nueva) los posibles riesgos de disolución e instrumentalización de la perspectiva estética por parte de las otras perspectivas, es decir, tanto, por ejemplo, desde la acción política como desde el impactante desarrollo de los medios tecnológicos? ¿No es ésta, ciertamente, la sugestiva historia de la génesis y general implantación, de manera progresiva, de la actual estética difusa?

Por tanto, se nos ofrece así, a través del arco histórico conformado por el último siglo, toda una saga de rupturas y transformaciones, pero quizás también -como intentamos subrayar- un sugerente rosario de múltiples enlaces y continuidades muy significativas.

¿En qué sentido cabe hablar, pues, de continuidad y/o de diversificación entre los planteamientos que corresponden a la estética generalizada de las vanguardias y aquellas otras opciones que han venido marcando un claro predominio por parte de la esteticidad difusa, en esta coyuntura tardomoderna?

Quizás convenga acentuar-como un posible hilo conductor, que zigzaguea entre los extremos del continuum que venimos perfilando- la relevancia concedida ya en el seno de las propias vanguardias al papel de la creación artística de una segunda naturaleza y a la paralela producción de simulacros. Tales postulados, de alguna manera llegarían -en su devenir- a enlazar asimismo directamente, y a converger, con la preponderante implantación, en nuestro 
actual contexto existencial, de una segunda realidad electrónica, dotada muy especialmente de un eficaz e impactante carácter básicamente espectacular.

Históricamente, como es bien sabido, las propuestas de creación artística de una segunda naturaleza supusieron, por parte de las vanguardias, la abierta y decidida ruptura del orden de representación naturalista para dar paso franco y decidido a un nuevo arte, como síntesis constitutiva de un mundo propio, es decir como diseño de una nueva realidad. Con ello, por cierto, cristalizaba a marchas forzadas la racionalidad productiva, se acentuaba el poder de la revolución radical y se vinculaba estrechamente la creación artística con el logos histórico de una praxis social que se pretendía, ante todo, claramente emancipadora.

Al fin y al cabo -dejémoslo bien claro- se trataba de construir una nueva realidad como obra de arte total. Y, de este modo, la dimensión artística se elevaba al grado máximo de principio uniformizador de cualesquiera otras actividades humanas. La estética generalizada se perfilaba, evidentemente, como radicalizada utopía antropológica.

Sin embargo, a decir verdad, ¿dónde quedaban las particulares experiencias del sujeto en relación a la concreta realidad circundante, siendo así que se planteaba, a ultranza, la creación de otra realidad -como efectivo simulacro- transformada en obra de arte total, en cuyo seno, por ejemplo, las nuevas estrategias lingüísticas de fragmentación y descontextualización jugaban, programáticamente, en beneficio de una alternativa esteticidad espectacular? A esta situación de creciente merma de la experiencia empírica individual tendremos que volver, en nuestras posteriores reflexiones.

Por otra parte, ya hemos apuntado que esa postulada integración entre arte y praxis vital significó asimismo, por un lado, la incorporación de la perspectiva estética a las nuevas formas incisivas de propaganda política, así como de intensa y abierta publicidad comercial y supuso igualmente, además, la efectiva asimilación de la perspectiva tecnológica como paradigma fundamental de las auspiciadas metas civilizatorias, anticipándose incluso ambiguamente, de este modo, a determinadas estrategias posteriores de abierto consumo mercantil de tales productos nacidos de la alta tecnología.

De hecho, la racionalidad inherente al progreso industrial, el principio de la obra de arte total y la correspondiente producción de simulacros y de una nueva realidad, como vertientes fundamentales de la dialéctica de las vanguardias, quizás no fueron en absoluto ajenas tampoco -en su conjunto- a las consecuencias históricas de su abierta institucionalización y mercantilización. Lo cual, por cierto, no tendría por qué implicar, de por sí, descrédito alguno -en la relectura de las vanguardias- sino la evidencia de la consumación de su propio desarrollo interno, justamente en el encuentro histórico que acontece con determinadas condiciones externas, quizás inopinadamente sobrevenidas. 
Así pues, tanto las opciones vanguardistas que exhiben los valores de un racionalismo funcional (neoplasticismo, constructivismo) como las que se decantan hacia un radical irracionalismo (surrealismo) convergen mutuamente -como hemos dicho- en sus objetivos de crear una segunda realidad artificial, es decir un universo de simulacros y de objetos de deseo, bien sea, en un caso, bajo los auspicios de la producción y la racionalidad tecnocientífica, o bien, en el otro, bajo el punto de vista del principio fetichista y de consumo.

En consecuencia, tras esa nueva construcción de la realidad y ese postulado/deseado universo de simulacros, se evidencian, en cualquier caso, las comprometidas estrategias de transformación artística de la sociedad, del logro de nuevas metas educativas y de calidad de vida, tras la impronta de un programa de eficaz estética generalizada en su compenetración de principios e intercambio de significados con lo tecnológico, lo político y lo económico.

Sin embargo, el espíritu de la modernidad que dinamizaba el desarrollo de las vanguardias no sólo soplaba al socaire de un idealismo revolucionario, como planificado fulcro emancipador. Insistentemente conviene recordar también que la construcción artística de la nueva realidad suponía asimismo la industrialización del diseño, la racionalización de las formas, la publicitación de sus logros, la subordinación del espacio y el tiempo a un principio de eficacia técnica y económica o la legitimación de la técnica como elemento civilizador.

La progresiva estetización de la política e incluso de la vida cotidiana, mediante la planificada instrumentalización de la perspectiva estética desde y por parte de la perspectiva tecnológica, a partir ya de los presupuestos mismos de las poéticas de vanguardia, sin duda preanunciaban, de manera bastante clara, el decantamiento que, a decir verdad, conduce de la revulsiva -aunque arriesgadamente ambigua- estética generalizada a la sofisticada esteticidad difusa, posterior.

\section{III}

Pero centrándonos ya en el contexto presente, ¿qué rasgos podríamos adscribir a la actual situación mediática, con la que paradigmáticamente suelen correlacionarse, de forma insistente, los planteamientos de la estética difusa?

Ante todo, consideramos la necesidad de subrayar simultáneamente, en esta aproximación al tema, dos notas claves y definitorias: fascinación/entusiasmo e inquietud, como rasgos básicos y caracterizadores de la presente coyuntura.

Por un lado, fascinación y entusiasmo provocados ya a partir del propio grado de desarrollo tecnológico alcanzado, así como por los espectaculares efectos de esa hiperrealidad, que estéticamente ha heredado -e intensificado-los presupuestos de la obra de arte total, interrelacionando plenamente, por este camino -ahora sí-, las citadas perspectivas tecnológicas, estéticas y políticas. 
Lógico es que -antes o después- junto a tal fascinación, emerja asimismo una determinada inquietud y sospecha frente a toda una serie de destacados factores, como puedan serlo, por ejemplo, las nuevas fronteras socioculturales electrónicamente perfiladas, e incluso la constatación del paulatino empobrecimiento de las culturas históricas o el amago simultáneo de una creciente dominación mediática, toda vez que en la imparable automatización de nuestro entorno, con la producción y difusión masivas de una realidad técnicamente (re)producida, se restringen de manera drástica -en líneas generales- las posibilidades de fijar y comunicar las formas de las experiencias personales, mediadas habitualmente por procesos reflexivos autónomos y ligadas además a la memoria histórica colectiva, siempre en la vieja línea auspiciada por nuestra tradición de cultura.

Ciertamente, la estética difusa participa directamente en la creación programada de una obra de arte total y también en la elevación de la nueva realidad, tecnológicamente producida, a ese singular e inusitado grado formal de intensidad estética. Es lo que podemos calificar resueltamente como proceso de estetización de la comunicación electrónica.

Se trata plenamente -como innegable logro histórico- del simulacro compartido de una segunda naturaleza global, cuya comunicación social se transforma en ritual participativo y celebración colectivas, acentuándose, de este modo, la fruición e identificación del individuo en torno a creencias, mitos y símbolos comunes, gracias, especialmente, al impacto expresivo de los nuevos medios y a sus eficaces funciones acaparadoramente vinculantes.

En realidad, si reflexionamos, en este sentido, en torno al actual universalismo electrónico de los medios podremos reencontrar las huellas de aquellas opciones centrales que históricamente inspiraron y presidieron los programas de la revolución vanguardista, tales como la ruptura con la tradición, la abstracción de la realidad gracias a la creación de nuevos lenguajes artificiales, descontextualización y fragmentación de las imágenes respecto a su espacio y tiempo propios, la construcción de objetos, es decir de dispositivos artísticos, planteados como una segunda naturaleza o simulacro de lo real y, especialmente -como venimos insistiendo- la instauración de la historia y la sociedad como espectáculo global compartido y disponible, como obra de arte total.

Sin embargo, la nueva estética difusa tiende asimismo -al menos, desde la óptica del sujeto- a la restricción o abolición mediática del «punto de vista», de la reflexión y de la conciencia. Desde el ángulo de los dispositivos estéticos, ya hemos subrayado que se acentúan simultáneamente tanto el carácter fragmentario, combinatorio y descontextualizador de las imágenes como sus rasgos de totalidad dramatizada y espectacular.

Es por esta vía como se postula la absolutización de su valor icónico y comunicativo (convertido, como tal, en una dimensión consagrada) sin pre- 
ocuparse, en igualdad de condiciones, por la posible insignificancia (pérdida de significación) de sus valores intrínsecos, es decir, sin replantearse el hecho de su posible trivialidad y ligereza.

La estética difusa, que nos ocupa, refuerza, de esta manera, los correspondientes efectos de la revolución electrónica: su valor pragmático, manipulativo y configurador de la conciencia y de la cultura, como una totalidad inherente a los mass media. Diríamos que acentúa más su interés por los inmediatos efectos sociales de la imagen que por sus posibles significados. Se trata, en consecuencia, de la reducción de lo real a imagen, de su transformación en estricto y potente espectáculo. En última instancia, del culto a la imparable función efectista.

¿Cabe plantear que la auténtica paradoja de la esteticidad difusa consiste en el hecho de que paralelamente a los procesos de estetización de la comunicación electrónica (es decir de la estetización de la política, de la publicidad, del ocio y de la vida en general, en los que eficazmente toma parte activa), a su vez -como hemos sugerido-conlleva y conduce, en realidad, al efecto sesgado de la estricta abolición de la experiencia estética (en el sentido integrador de «experiencia personal de plenitud», subrayado reiteradamente en la tradición histórica de la modernidad) así como de la correspondiente precariedad de la propia conciencia y experiencias individuales?

Su directa participación en la hiperrealidad de los medios de comunicación repercute en menoscabo de toda experiencia subjetiva «inmediata», anulando -haciendo abstracción de- las posibles condiciones individuales y cotidianas de la existencia humana. (Se trata de la condición electrónica de la mengua creciente de la experiencia, del distanciamiento ascético, de la renuncia a la inmediatez táctil, al contacto personal, a la percepción inmediata, a la relación intuitiva con el entorno físico). Con ello se produce la creciente volatización de la realidad como algo inmediato e individualizable, en favor de una realidad «artificial» o mediatizada, sustitutiva y efectivamente catártica.

La esteticidad difusa, con el respaldo tecnológico, ayuda pues tanto a la intensificación de la imagen -fundamento clave de su eficacia- como a nuestra plena inmersión en ella. Pero, diferenciándose de la propia experiencia estética, tiende más bien a disminuir la distancia entre el espectador y la obra, a la vez que aumenta la separación entre la colectividad de los espectadores y la realidad exterior. Es el resultado de esa doble condición antinómica de distancia y proximidad con respecto al objeto hiperreal: por un lado, de mediación técnica y manipulativa, y, por otro, de cercanía reproductiva y poder mágico.

Sin duda, una cosa es la ampliación de la realidad y la extensión que los medios tecnológicos pueden aportar a las experiencias y facultades humanas y otra muy diferente es la sustitición de la realidad y la precarización de la conciencia -por ejemplo- mediante procesos, complementarios entre sí, de 
gratificación furtiva de deseos narcisistas, de contemplación trivializada o de insistencias repetitivas, potenciadas a través del efecto banalizador de la cultura espectacular y mercantil, con sus consabidos paquetes informativos, sus recurrentes mecanismos psicocomerciales o la creación dramatizada de identidades subjetivas, tan efímeras como intercambiables.

De hecho, la estética difusa colabora por igual tanto en la desrealización de las experiencias autoconscientes como en la supresión de sus referentes históricos y sociales. Así, las experiencias mediadas -que nos facilita con generosidad esa misma estética difusa- tecnológicamente potenciadas, lejos del aquí y el ahora personal, implican una constante movilidad sin anclajes y una total liberalización de referencias, promovidas por la hiperrealidad o por la realidad virtual, asumidas, en cualquier caso, como simulacros claramente alternativos y sustitutorios.

En consecuencia, la mirada que demanda y provoca la esteticidad difusa es una mirada saturada de carácter ritual, de fruición espectacular y no reflexiva. Una mirada capaz de barajar la neutralización de la experiencia humana con la acrecentada apetencia fruitiva, junto con una determinada dosis de ataraxia. (Sirva de ejemplo la habitual indiferencia respecto a los contenidos efectivos del flujo mediático, donde -merced a su plural diseminación-pueden cohabitar la publicidad y la violencia, el erotismo y la información política, en el mismo hilo, con la viveza y la fragmentada continuidad del espectáculo).

La estética difusa se fundamenta, pues, y gira en torno a esa charnela que implica tanto el creciente confinamiento de la experiencia autoconsciente y reflexiva como la exclusión de lo real, en cuanto condiciones externas de la reproducción mediática. Pero además implica toda una serie de condiciones internas, propias del lenguaje de los medios electrónicos, que suponen -en la edición de las imágenes- el corte y la fragmentación, el aislamiento y la descontextualización, la sutura narrativa y el montaje, la intertextualidad y las contaminaciones encadenadas.

Es decir, que los procedimientos técnicos del universo mediático, a la vez que construyen su propio ámbito hiperreal, definen paralelamente la condición delimitada, custodiada y sitiada de la realidad, al segregarla y excluirla de sus propias condiciones espaciales y temporales. Y también la alejan -y nos distancian- de su inmediata experiencia cognitiva, porque simultáneamente a la producción de otras realidades motivan y producen -en un mismo paquete- las actitudes humanas frentes a ellas.

Es decir, que, de hecho, formateando, componiendo y organizando -técnica y estéticamente- la realidad, los nuevos medios condicionan y configuran asimismo nuestras relaciones no sólo con esa otra hiperrealidad, sino también con nuestro propio medio cotidiano. El universo electrónico parece desarrollar así su propia y eficaz paideia. 


\section{IV}

Sin embargo, conviene tener en cuenta, al menos, otro par de perspectivas, que consideramos de sumo interés.

Por un lado, se trata de hacer hincapié en la coexistencia antropológica que paralelamente mantenemos tanto con la comentada dimensión hiperreal, que desarrollan los medios tecnológicos, como con el ámbito de la realidad cotidiana, aunque ésta esté estrechamente correlacionada con aquélla. No en vano se trataría de reivindicar la vida cotidiana como el espacio en el que propiamente tienen lugar la experiencia y la conciencia individuales, toda vez que la vida cotidiana podría actuar englobando todas las otras posibles «realidades» a las que, de alguna manera, nos enfrentamos sin parar.

Sería en ese doble encuentro -¿escindido? - del sujeto con la realidad cotidiana y con la hiperrealidad de los medios donde, al fin y al cabo, debería jugarse la fundamental y definitiva partida de la educación: la de realizar la imprescindible síntesis personal entre experiencia y consciencia.

¿Cómo eludir, pues, la necesidad de plantear -una vez más- la restauración de los derechos de la autonomía de la experiencia subjetiva?

Quizás no esté de más apuntar concretamente las posibilidades de rescatar la experiencia subjetiva bien sea por la vía de la efectiva reflexión crítica sobre la situación presente y/o, alternativamente, por la vía de la acción creativa a partir del recurso a los propios medios, es decir la oportunidad de activar la apropiación dionisíaca de los resortes tecnológicos, o sea la conversión de la tecnología en técnica artística, esquivando así la situación escindida de la estética difusa. Este sería, sin duda, el sendero a transitar.

No en vano, esta última sugerencia -ahora simplemente apuntada- enlaza directamente con la otra perspectiva que queríamos subrayar: la conveniencia de pensar asimismo la cultura más allá de su dimensión de espectáculo o de estricto consumo, para reivindicar justamente la cultura, ante todo, como espacio de producción simbólica. A decir verdad, toda producción simbólica -en cuanto dimensión comunicativa de la producción social de la existencia humana-desempeña un papel clave en la construcción de la realidad, actuando como mediadora entre la experiencia y la conciencia en el ámbito preferente en el que éstas desarrollan y funden su unidad: la citada realidad cotidiana.

¿Por qué no intentar, de hecho, ir más allá de cualquier proyecto político y social que dé total preeminencia a las aptitudes de contemplación y de consumo sobre/frente a otras posibles aptitudes activas y participativas? ¿Acaso no podemos ser todos, democráticamente -en determinados grados y en ciertas circunstancias- productores y consumidores de bienes culturales?

Es cierto que en el campo actual de la cultura, sumamente poliédrico -en el cual se alojan asimismo las manifestaciones del arte contemporáneo- se han 
asumido, en líneas generales, como rasgos intrínsecos y característicos de la misma, (a) la tendencia sistemática a la espectacularización tanto como forma de exposición y de difusión como en lo tocante a la gestión y producción, y (b) la banalización creciente de los contenidos vehiculados.

Sin duda, profundizar en los fundamentos democráticos de las políticas culturales significa, ante todo, dejar de pensar en la cultura exclusivamente desde la perspectiva del espectáculo, de la banalización y del estricto consumo. La cultura es producción antes que consumo y es también recepción crítica. Y cualquier objetivo que suponga democratizar los procesos culturales significa e implica, ciertamente, democratizar el consumo, pero también, y en igual medida, supone asimismo democratizar la producción y el discurso reflexivo y crítico sobre los resultados obtenidos. Significa, en definitiva, que todos deberíamos ser simultáneamente productores y receptores críticos de bienes culturales.

De ahí que el auténtico reto educativo de las políticas culturales debería orientarse prioritariamente hacia el objetivo de hacernos competentes en los diferentes lenguajes que vehiculan la expresión cultural, facilitando nuestra efectiva intervención y uso de los mismos. Sólo así podrá entenderse la cultura como un espacio real de participación, en el cual hay cabida para ejercitar plenamente la experiencia individual, es decir, dar cancha y posibilidades al ejercicio creador y reflexivo.

Quizás todo ello sólo sea un horizonte meramente posible, pero en tal espacio de inmediata participación personal, en el panorama de la cultura, de nuevo la estética generalizada reclamaría sus (utópicos) derechos, de la mano de un cierto activismo ciudadano. Si la estética difusa se consolida, a marchas forzadas, sobre todo en los ámbitos públicos e institucionales, gracias al pleno acceso a los dominios y recursos de la alta tecnología -a través de la espectacularización de sus formas y la banalización de sus contenidos- obligado será hacer un esfuerzo por asegurar la participación de la ciudadanía crítica en tales contextos, aunque ésta quede reducida, en su concepción de la cultura, a pequeños colectivos o personalidades aisladas de fuerte caracterización.

Sin duda, una de las formas más instauradas de estética difusa, en el marco de la cultura urbana actual, es la que se establece y manifiesta concretamente como propaganda institucional (museos, edificios, programas audiovisuales concretos, eventos festivos o bienales). Frente a este fenómeno básicamente contemporáneo, precisamente por la potencia y el alcance de los medios económicos y tecnológicos utilizados, la conciencia la mirada ciudadana puede mantenerse completamente al margen o involucrarse abiertamente en la estela de tales manifestaciones culturales/artísticas de poder. El hecho de que se bifurquen sus reacciones críticas (colectivas o personales) bien a favor o en contra, bien exponiendo discursivamente sus planteamientos o silenciándolos 
y manteniéndolos de manera exclusiva, a escala individual, no son sino modalidades distintas a tener siempre en cuenta.

Pero la estética difusa, hoy cada vez más imperante y resolutiva no sólo en el dominio general de la cultura sino también en el contexto del arte contemporáneo, exige, al menos, a nuestro modo de entender, esa intensa mirada crítica para sopesar sus efectos, analizar sus funciones y diversificar su alcance. 